\title{
THE INDICES OF POTENCY FOR INTRAVENOUS ANAESTHETICS
}

\author{
Igor Kissin, TOM MCGeE AND Lloyd R. SMITH
}

\begin{abstract}
In rat experiments. the relative potency and safety of thiopentone, diazepam and etomidate were assessed using different indices of anaesthesia - loss of righting reflex, prevention of movement and heart rate responses to an noxious stimulus. Log-probit dose-response curves for these end-points and for lethal effect were determined. Etomidate proved to be more potent than thiopentone or diazepam; its relative potency figures varied from 5 to 18 with the use of different end-points of anaesthesia. According to the ED50 level of response for the loss of righting reflex and increase of heart rate, diazepam was more potent than thiopentone. At the same time it was less potent in the prevention of movement response. Etomidate has an extremely large standard safety margin (SSM) regarding the loss of righting reflex; with the use of movement response or heart rate response, the SSM for etomidate was close to that of thiopentone. With diazepam, SSM for movement response and heart rate response was negative (anaesthetic dose-response curve partially overlaps the lethal curve); it was positive for the loss of righting reflex.

The extreme variability in assessment of relative potency and safety with different end-points of anaesthesia probably indicates that the indices used reflected various components of anaesthesia. It seems likely that for the proper assessment of the potency of intravenous anaesthetics, one index of potency is not sufficient. Several indices of potency corresponding to different components of general anaesthesia must be used.
\end{abstract}

Key Words: Anaesthetics, intravenous, relative potency; thiopentone, diazepam, etomidate.

IN ANIMAL EXPERIMENTS, relative potencies of anaesthetics are usually determined by using one index of anaesthetic action. The comparison is based either on the loss of righting reflex or on prevention of movement response to a noxious stimulus. It is well known that general anaesthesia includes various components. Woodbridge ${ }^{1}$ described the following components or elements of anaesthesia: sensory block, motor block, block of reflexes, and mental block. If the strength of anaesthetic action is equally related to all components of anaesthesia, one index of anaesthetic potency would be sufficient to compare different general anaesthetics. However, if the opposite is true, this would indicate a need for the use of several indices corresponding to different components of anaesthesia.

In the present study, several intravenous anaesthetics were compared using different indices of anaesthetic potency to determine to what

Igor Kissing, M.D., Ph.D., Associate Professor of Anesthesiology; Tom McGee, B.S., Research Technician, Department of Anesthesiology; Lloyd R. Smith, M.A., Data Manager, Clinical Cardiovascular Computer Center; School of Medicine, University of Alabama in Birmingham, Birmingham, Alabama 35294 , U.S.A. 585 extent the assessment of relative potency and safety of anaesthetics is influenced by the type of index chosen. It has been noted previously that the interpretation of relative potencies of anaesthetics is affected by the slopes of their quantal dose-response curves. ${ }^{2,3}$ If two agents do not have parallel dose-response curves, their relative potencies are different at each level of response. The same is true in the assessment of the margin of safety of anaesthetics which is dependent on the relative position of dose-response curves for anaesthetic and lethal effects. Taking this into account, we compared the dose-response curves at different levels and estimated their slopes. Dose-response curves for thiopentone, diazepam, and etomidate were determined for different end-points of anaesthesia. Dose-response curves for a lethal effect were also determined to calculate and assess standard safety margins.

\section{METHODS}

The experiments were done on male SpragueDawley rats weighting $225-250 \mathrm{~g}$. Dose-response curves for three different end-points of anaesthesia and for the lethal effect were determined with 
each drug. The following end-points of anaesthesia were used:

1. Loss of righting reflex. The test was regarded as positive if a rat failed to right itself from a side position for 15 seconds.

2. Prevention of movement in response to a noxious stimulus. ${ }^{4}$ The animals were stimulated for $60 \mathrm{sec}$ by placement of a weight of $1 \mathrm{~kg}$ on the middle of the tail (pressure surface of $0.25 \mathrm{~cm}^{2}$ ). Only the purposeful movement of the head or legs was taken into account as a response. Stiffening, coughing, hyperventilating, or vocalizing were not considered.

3. Prevention of the rise in heart rate in response to a noxious stimulus. Stimulation was the same as for the movement response. The heart rate was derived from the electrocardiogram. A cardiotachometer triggered by electrocardiographic signals provided records of heart rate on a Grass 7-D polygraph. Increase in heart rate less than one per cent was regarded as a negative response. (When anaesthesia was superficial, the heart rate response usually reached 7-10 per cent.)

Thiopentone, diazepamt, and etomidate* were injected into the saphenous vein. Volume of the injected solution was $0.5-1.0 \mathrm{ml}$ and duration of the injection was 30 seconds. The endpoints of anaesthesia were determined two minutes after the injection. (It was found in preliminary experiments that thiopentone and etomidate cause the maximal effect in one minute after the completion of intravenous injection and this effect did not change during the second minute following the injection. At the same time, with diazepam the anaesthetic effect in many cases was maximal only in two minutes following drug administration. Therefore, a two minute interval has been chosen for comparison.) In the series of experiments where lethal doses of the drugs were administered, a 24 hour time interval was used to define death. (All except for several animals which died within 15 minutes after the injection. Therefore, the results obtained with the 24 hour time interval were not significantly different from the results with the 15 minute time interval.)

With each of the three drugs under investigation, four series of experiments were done: for the righting reflex, movement response, heart rate response, and lethal effect. In each series of experiments, five groups of five rats constituted a dose-response curve. In one group of animals,

*Courtesy of Janssen Pharmaceutica †Courtesy of Hoffmann-LaRoche. the dose of the drug was low enough so that all animals were unaffected and, in another group, it was high enough so that all were affected. Dose levels for these two groups were found in preliminary experiments. In the three remaining groups, the doses of the drug were equally spaced between the above mentioned marginal doses.

For calculation of dose-response curves, we used the probit method of statisical analysis. Percentage of positive effects were converted into probit values (multiples of the standard deviation) and plotted against a log of the doses. This converts the sigmoid dose-response curve into a straight line and facilitates comparisons. All calculations were performed with the use of the probit procedure in $\mathrm{SAS}^{5}$ on an IBM 370 computer. The procedure was a non-linear least squares technique based on the method of Finney. ${ }^{6}$

The following data were derived:

(a) ED1-ED99 for the three end-points of anaesthesia, as well as LDI-LD99.

(b) The slopes of log-probit dose-response lines for the three end-points of anaesthesia and for the lethal effect.

(c) Standard safety margin, ${ }^{7}$ SSM $=$ LDI ED99/ED99 $\times 100$. SSM is the percentage by which the ED99 has to be increased before the LDI is reached. In contrast to the therapeutic index, SSM is influenced not only by the distance between central points of the anaesthetic and lethal dose-response curves, but also by the slopes of these curves.

\section{RESULTS}

Dose-response curves reflecting different endpoints of anaesthesia and lethal effect for thiopentone, diazepam, and etomidate are presented in Figures 1, 2, and 3. Comparison of the doseresponse curves reveals an extreme variability in their location along the dose axis. Central points of the dose-response curves represent median effective doses (EDS0). In numerical form, they are summarized in Table $I$. As it follows from this table, ED50 with the loss of righting reflex and blockade of heart rate response for diazepam is smaller than the respective doses for thiopentone $(p<0.05$ ). at the same time, ED50 with prevention of movement response for diazepam is greater than that for thiopentone ( $p<0.00 \mathrm{l}$ ). ED50 for etomidate with all end-points of anaesthesia are many times less (from 5 to 18) than those for the two other agents. LDS0 for etomi- 


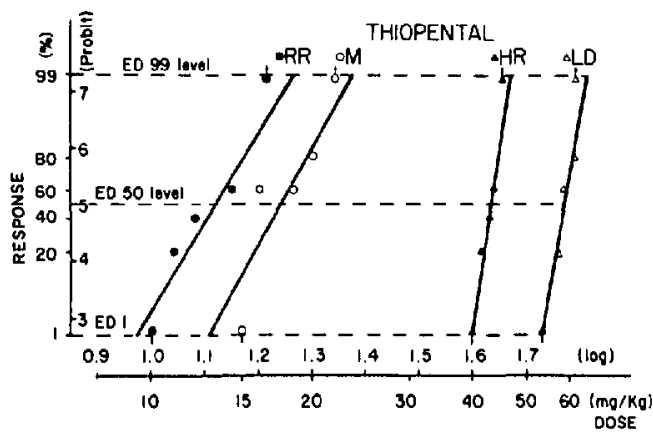

Figure 1 Dose-response curves for thiopentone with different end-points of anaesthesia and lethal effect. $R R$ - loss of righting reflex. $M$ - prevention of movement in response to a noxious stimulus. HR prevention of heart rate increase in response to a noxious stimulus. LD - lethal effect. Each point represents the incidence of the effect in a group of five animals at the indicated dosage.

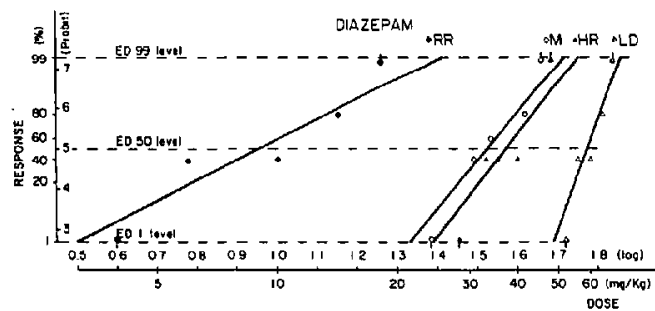

FIguRE 2 Dose-response curves for diazepam with different end-points of anaesthesia and lethal effect.

date was approximately 3 times less than LD50 for thiopentone and diazepam.

Slopes of the dose-response curves in numerical form are presented in Table II. The differences are not restricted between the various agents. With the same agent, dose-response curves reflecting different end-points of anaesthesia often have different slopes. In the case of the thiopentone the slope of dose-response curve for heart rate response is different from the curve slopes for the righting reflex and movement response ( $p<0.02$ ). Diazepam has parallel curves for heart rate and movement response; however, the curve slope for the righting reflex is different ( $p<0.05$ ). With etomidate, the curve slope for movement response is much flatter than those for the two other end-points of anaesthesia $(p<0.05)$.

Standard safety margins (SSM) regarding different end-points of anaesthesia for thiopentone and etomidate are presented in Figure 4. In comparison with thiopentone, etomidate has an extremely large SSM with the loss of righting reflex. At the same time, the differences between
SSM for etomidate and thiopentone with movement response and heart rate response are not very pronounced.

\section{Discussion}

Our results show that the relative potencies of thiopentone, diazepam and etomidate vary significantly with the use for comparison of different end-points of anaesthesia. Drug relative potencies based on the ED50 values (see Table I) vary for diazepam from 0.5 to 1.3 and for etomidate from 5.3 to 15.0. In order to prevent movement response, thiopentone is twice as potent as diazepam. At the same time, with the use of righting reflex, diazepam is more potent that thiopentone.

An additional factor for variability in relative potency assessment is the slope of dose-response curve. If compared drugs do not have parallel dose response curves, their relative potencies are different at various levels of response. Figure 5 shows that at ED50 level of response (loss of righting reflex), diazepam potency in comparison with thiopentone is 1.3. However, at levels lower than ED50, the relative potency of diazepam increases, and at higher levels, it decreases to the degree of less than one.

Our data show that the slopes of dose-response curves, even for the same agent, are varied for different end-points of anaesthesia. Therefore the relationship between the curve slopes of two compared intravenous anaesthetics may also be variable with different end-points of anaesthesia. For example, the slopes of the dose-response curves for thiopentone and diazepam with the righting reflex were 16.6 vs 4.8 , and with movement response 16.9 vs. 11.7 .

Etomidate has an extremely large margin of safety with the loss of righting reflex. In our experiments, ED50 for the loss of righting reflex and LD50 were $0.86 \mathrm{mg} \cdot \mathrm{kg}^{-1}$ and $20.4 \mathrm{mg} \cdot \mathrm{kg}^{-1}$, respectively. These values agree well with those reported by Janssen et al. (ED50 $-0.92 \mathrm{mg} \cdot \mathrm{kg}^{-1}$, LD50-26.1 mg $\mathrm{kg}^{-1}$, for the rats of $200 \mathrm{~g}$ at a two minute rate of drug infusion). ${ }^{8}$ Slopes of doseresponse curves of the intravenous anaesthetics affect the assessment of their safety. Therefore, SSM which is influenced not only by the distance between ED50 and LD50 but also by the slopes of the dose-response curves, is always less than LD50/ED50 ratio. For etomidate, SSM was 858 per cent with the loss of righting reflex (Figure 4). With the use of movement response or heart rate response, SSM for etomidate were close to those 


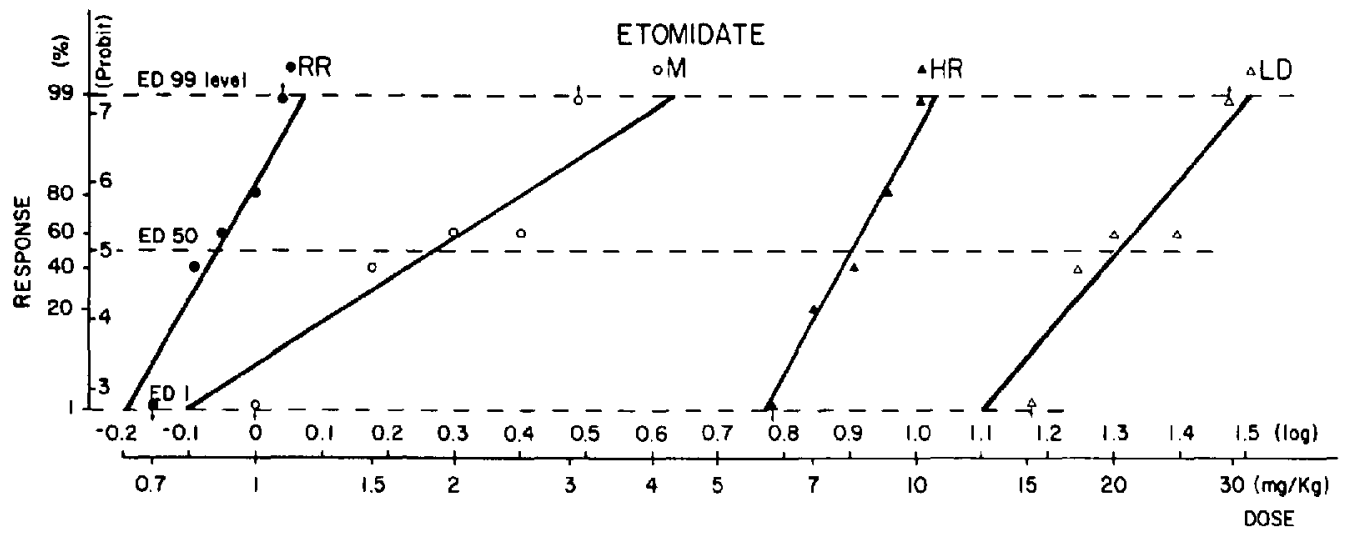

FIGURE 3 Dose-response curves for etomidate with different end-points of anaesthesia and lethal effect.

TABLE I

Median Effective Doses $\left(\mathrm{mg} \cdot \mathrm{kg}^{-1}\right.$, i.v.) of Thiopentone, Diazepam and Etomidate For DiffEREnT END-POINTS of ANAESTHESIa

\begin{tabular}{|c|c|c|c|c|}
\hline & $\begin{array}{l}\text { Loss of } \\
\text { righting } \\
\text { reflex }\end{array}$ & $\begin{array}{l}\text { Prevention } \\
\text { of movement } \\
\text { response }\end{array}$ & $\begin{array}{c}\text { Prevention } \\
\text { of heart rate } \\
\text { response }\end{array}$ & $\begin{array}{l}\text { Lethal } \\
\text { effect }\end{array}$ \\
\hline Thiopentone & $\begin{array}{c}12.9 \\
11.2-14.1^{*} \\
(1.0)\end{array}$ & $\begin{array}{c}17.2 \\
15.0-18.8 \\
(1.0)\end{array}$ & $\begin{array}{c}42.6 \\
41.7-44.1 \\
(1.0)\end{array}$ & $\begin{array}{c}57.8 \\
56.0-59.4\end{array}$ \\
\hline Diazepam & $\begin{array}{c}9.7 \\
5.8-12.6 \\
(1.3)\end{array}$ & $\begin{array}{c}34.5 \\
28.5-39.3 \\
(0.5)\end{array}$ & $\begin{array}{c}37.6 \\
33.2-44.0 \\
(1.1)\end{array}$ & $\begin{array}{c}59.6 \\
55.6-63.1\end{array}$ \\
\hline Etomidate & $\begin{array}{c}0.86 \\
0.77-0.95 \\
(15.0)\end{array}$ & $\begin{array}{c}1.9 \\
1.3-2.4 \\
(9.0)\end{array}$ & $\begin{array}{c}8.1 \\
7.2-9.2 \\
(5.3)\end{array}$ & $\begin{array}{c}20.4 \\
16.7-24.7\end{array}$ \\
\hline
\end{tabular}

*95 per cent fiducial limits.

Parentheses include relative potencies of agents based on ED50 values.

TABLE II

Slopes of Log-Probit Dose-Response Curves for Thiopentone, Diazepam and ETOMIDATE for Different END-Points of ANAEsthesia ANd Lethal EfFect (Рrobit/Log Dose Ratio)

\begin{tabular}{lcccr}
\hline \hline & $\begin{array}{c}\text { Loss of } \\
\text { righting } \\
\text { reflex }\end{array}$ & $\begin{array}{c}\text { Prevention } \\
\text { of movement } \\
\text { response }\end{array}$ & $\begin{array}{c}\text { Prevention } \\
\text { of heart rate } \\
\text { response }\end{array}$ & $\begin{array}{c}\text { Lethal } \\
\text { effect }\end{array}$ \\
\hline Thiopentone & 16.6 & 16.9 & 80.2 & 69.6 \\
Diazepam & 4.8 & 11.7 & 12.8 & 29.8 \\
Etomidate & 18.1 & 6.4 & 17.8 & 9.4 \\
\hline
\end{tabular}

for thiopentone. With diazepam, anaesthetic dose-response curves for movement response and heart rate response partially overlapped the lethal curve (Figure 2).

Some of our dose-response curves paralleled others; others did not. Absence of parallelism between dose-response curves for different endpoints of anaesthesia for the same agent suggests that different mechanisms of action might be involved in such cases. It is of interest to note that when the curves slopes for different end-points of anaesthesia with diazepam and thiopentone were similar, such curves were place close to each other on the dose axis (righting reflex and movement response for thiopentone, movement response and heart rate response for diazepam).

With special reference to anaesthesia, Waud and Waud have introduced the term "ordered responses" for handling the depth of anaesthesia as a graded process (Guedel's classification, a 


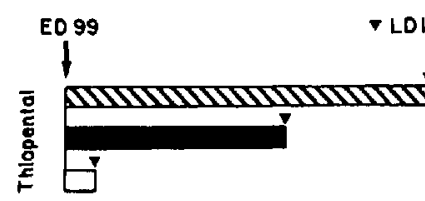

Righting

Reflex

Movement

Response

Heort Rato

Response

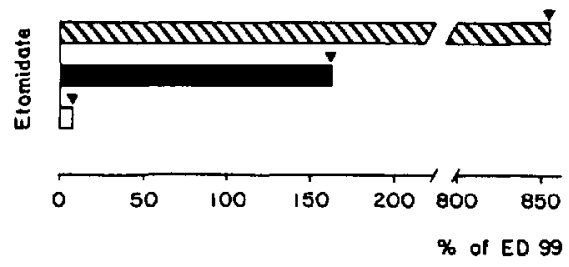

FIGURE 4 Standard safety margins (SSM) for thiopentone and etomidate with different end-points of anaesthesia. SSM = LDI - ED99/ED99 $\times 100$ shows the percentage by which ED99 has to be increased before the LDI is reached.

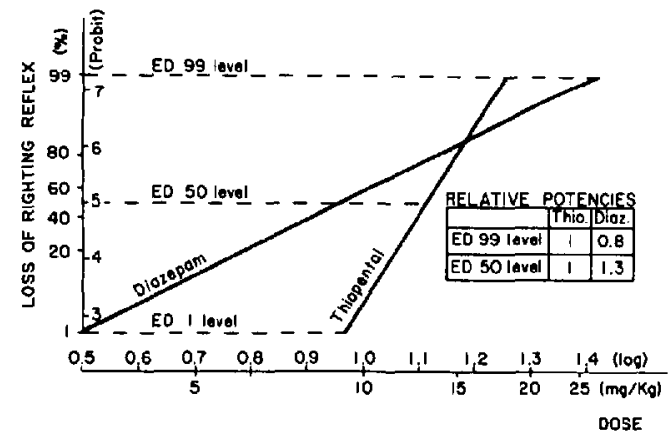

Figure 5 Relative potencies of thiopentone and diazepam for loss of righting reflex at different levels of response.

scale of electroencephalographic end-points). ${ }^{2}$ They underlined the drawback of this approach: "... distance between end-points can have no meaning". By placement of three dose-response curves for different end-points of anaesthesia along the dose axis, we created a kind of "ordered response" system. Extreme variability in the position of the dose-response curves for different end-points of anaesthesia, including their slopes, might be used as a confirmation of this opinion at least for intravenous anaesthetics.

Thus, there was an extreme difference in the assessment of relative potency and safety when different indices of anaesthetic potency were used. This difference was probably due to the fact that the indices used reflected various components of anaesthesia. A dose-response curve reflecting one component of anaesthesia cannot be used to define another component of anaesthesia. It seems likely that for the proper assessment of the potency of intravenous anaesthetics, several indices of potency corresponding to different components of general anaesthesia must be used. An additional reason for this may be the limitations due to the differences between end-points of anaesthesia used in animal experiments and in man.

\section{REFERENCES}

1. Wooderidge, P.D. Changing concepts concerning depth of anesthesia. Anesthesiology 18:536 (1959).

2. WAUD, B.E. \& WAUD, D.R. On dose-response curves and anesthetics. Anesthesiology 33: 1 (1970).

3. KISsin, 1. Bioassay, potency and intravenous anesthetics. Anesthesiology 53:351 (1980).

4. Eger, E.I. Anesthetic uptake and action. Baltimore, William \& Wilkins (1979).

5. SAS USERS GuIDE. The SAS Institute, Raleigh, N.C. (1979).

6. FInNeY, D.J. Probit analysis. London, Cambridge University Press (1952).

7. Foster, R.H.K. Standardization of safely margin. J. Pharmacol. Exp. Ther. 65: 1 (1939).

8. JANSSEN, P.A.J., Neimegeers, C.J.E. \& MARSBoom, R.P.H. Etomidate a potent nonbarbiturate hypnotic. Intravenous etomidate in mice, rats, guinea-pigs, rabbits and dogs. Arch. Int. Pharmacodyn 2/4: 92 (1975).

\section{RÉSUMÉ}

En expérimentant sur le rat, on a étudié la puissance relative et la marge de sécurité fournie par le thiopentone, le diazepam et l'étomidate par l'utilisation de diffërents critères d'anesthésie: l'abolition du redressement réflexe, la prévention du mouvement et la réponse de la fréquence cardiaque aux stimuli nocifs. Des courbes de relation dose-effet par la méthode de l'analyse des probits sur les critères déjà énumérés ainsi que sur la léthalité ont été dressées. On a trouvé l'étomidate plus puissant que le thiopentone et le diazcpam; sa puissance relative variait entre 5 et 18 selon les critères employés. Au regard de la dose efficace (ED50) sur l'abolition du redressement réflexe et sur l'augmentation de la fréquence cardiaque, le diazepam a été plus puissant que le thiopentone, mais moins puissant lorsque le critère utilisé était la prévention du mouvement. L'étomidate a une marge de sécurité standard extrêmement étendue lorsqu'on étudie l'abolition du redressement réflexe; par contre lorsqu'on étudie la prévention du mouvement ou la fréquence cardiaque, la marge de sécurité standard pour l'étomidate est 
très près de celle du thiopentone. Avec le diazepam, la marge de sécurité standard atteinte pour la prévention du mouvement et la fréquence cardiaque a été négative (la courbe dose-effet anesthésique chevauchant partiellement la courbe de léthalité), mais positive au regard du redressement reftexe.

La variabilité extrême dans l'évaluation de la puissance relative et de la sécurité d'emploi lors de l'étude de différents critères d'anesthésie indique probablement que les indices utilisés réflétaient plusieurs composantes de l'anesthésie. Il semble que pour l'évaluation appropriée de la puissance des anesthésiques intraveineux, un seul index de puissance ne soit pas suffisant et que plusieurs index de puissance correspondant aux différentes composantes de l'anesthésie générale devraient être utilisés. 